\title{
Enterobacterial Repetitive Intergenic Consensus Polymerase Chain Reaction (ERIC-PCR) Genotyping of Escherichia coli Strains Isolated from Different Animal Stool Specimens
}

\author{
Reza Ranjbar $^{1 *}$, Afsar Tabatabaee ${ }^{2}$, Payam Behzadi ${ }^{3}$, Rohollah Kheiri ${ }^{4}$ \\ 1. Molecular Biology Research Center, Baqiyatallah University of Medical Sciences, Tehran, Iran \\ 2. Dept. of Microbiology, Zanjan Branch, Islamic Azad University, Zanjan, Iran \\ 3. Dept. of Microbiology, College of Basic Sciences, Shahr-e-Qods Branch, Islamic Azad University, Tehran, Iran \\ 4. Water Quality Control Office, Alborz Province Water and Wastewater Company, Karaj, Iran
}

\begin{tabular}{c} 
KEYWORDS \\
\hline Escherichia coli \\
Consensus Sequence \\
Polymerase Chain Reaction \\
DNA Fingerprinting \\
\\
Article Info
\end{tabular}

Received 12 April 2016

Accepted 29 Aug 2016;

Published Online 29 Dec 2016;

\begin{abstract}
Background: Escherichia coli is a commensal-pathogenic organism, which includes a wide range of strains. Despite several advanced molecular-genomic technologies for detecting and identifying different strains of E. coli, Enterobacterial Repetitive Intergenic Consensus Polymerase Chain Reaction (ERIC-PCR) technique is a quick, sharp and cost effective fingerprint method. The major purpose of the present study was to determine the distribution of ERICs within E. coli strains isolated from different healthy animal stool specimens including hens, sheep, and cows, as an appropriate and quick molecular-genomic tool.
\end{abstract}

Methods: The animal stool samples were obtained during 1 year (October 2012 to October 2013), from animal husbandries around Tehran and Alborz provinces, Iran. After screening processes, the E. coli bacteria were isolated and cultured via standard microbiological methods. The DNA molecules of E. coli bacteria were harvested and Enterobacterial Repetitive Intergenic Consensus Polymerase Chain Reaction (ERIC-PCR) was applied for bacterial molecular genotyping. The ERICPCR products were run on $1 \%$ gel electrophoresis. The final images regarding gel electrophoresis banding patterns were used for dendrogram generation via the GelClust software.

Results: Of 120 isolated samples, 115 different strains were recognized as $E$. coli. The fingerprint patterns involved 380 to $3280 \mathrm{bp}$ bands. The predominant bands included $2900 \mathrm{bp}, 1200 \mathrm{bp}$, and $1200 \mathrm{bp}$ in stool samples of hens, sheep, and cows, respectively. The highest frequencies and diversities were seen among $E$. coli strains isolated from hens and sheep stool samples.

Conclusion: The DNA profiles were clearly detectable via specific fingerprint patterns. The ERIC-PCR seemed to be a good approach for molecular typing of $E$. coli strains isolated from different animal sources.

Corresponding Information: Dr. Reza Ranjbar. Molecular Biology Research Center, Baqiyatallah University of Medical Sciences, Tehran, Iran. Tel: +982188039883 Email: ranjbarre@gmail.com

Copyright $\odot$ 2016, IRANIAN JOURNAL OF PATHOLOGY. This is an open-access article distributed under the terms of the Creative Commons Attribution-noncommercia 4.0 International License which permits copy and redistribute the material just in noncommercial usages, provided the original work is properly cited.

\section{Introduction}

Escherichia coli includes a wide range of strains distributed in different ecosystems; from alimentary tracts in animals and humans to nature (1), however, it is usually found in the normal microflora of the human gastrointestinal tract and

is intricately involved in the lives of humans (2-

$3)$. Thus, E. coli consists of a large range of strains 
with huge diversity in their genomes (4). Some strains cause serious diseases, such as Urinary Tract Infections (UTI) (5). Uropathogenic Escherichia coli (UPEC) is the most frequent agent causing UTI in adults and children (6-7). There are different strains divided to commensalisms and pathogens (8-11). Nonetheless, Escherichia coli is recognized as an appropriate indicator for water fecal contamination by animal or human stool (12).

Large genetic variations are not distinguished throughout traditional microbiological and biochemical tests. Instead of traditional diagnostics, the application of modern and advanced technologies, such as molecular diagnostic tools and molecular fingerprints may be an appropriate choice in molecular epidemiologic investigations $(5,13$, 14).

Polymerase Chain Reaction-based techniques are accurate, rapid, reproducible, sensitive, specific and reliable diagnostics, which are used for determining different DNA fingerprints (15). Among several PCR-based tools, the Enterobacterial Repetitive Intergenic Consensus (ERIC) PCR is a simple, sharp and cost effective genotyping technology for discriminating different types of strains. Indeed, ERICs are recognized as mobile DNA particles in association with Miniature Inverted Transposable Elements (MITEs) (5, 13, 14, 16-22).

The ERIC sequences are recognized in a huge number of bacterial genomes, including Enterobacteriaceae family members including $E$. coli. The incomplete palindrome sequences are generally detected within transcribed areas in association with intergenic consensus. Moreover, there are different numbers of ERIC sequence copies among bacterial species. Interestingly, there is significant diversity of copy numbers among different strains of $E$. coli. This diversity evokes the evolution processes among bacterial strains within a particular species like E. coli (23-25).

The clonal variability in different bacterial species such as E. coli is performed by homolog primers to ERIC sequences, in which the appeared patterns are valuable for evaluating the phylogenetic closeness by the help of different types of software, such as GelClust (26).
For this reason, the major purpose of present study was to determine the distribution of ERICs within isolated strains of E. coli as an appropriate, simple and cheap molecular-genomic tool. An important point to consider is that there are different gold standards for determining E. coli strains. Therefore, the authors decided to use ERIC-PCR as an optional methodology in this investigation (27).

\section{Materials and Methods}

\section{Sample collection}

The animal stool samples were provided from healthy hens (50 cases), sheep (50 cases), and cows (20 cases) during 1 year (October 2012 to October 2013). This project is excluded from ethical limitations, because the animals were not touched directly by the authors.

\section{Phenotypic and biochemical properties}

The collected stool specimens were inoculated into Presence-Absence broth (PA broth) and incubated at $35 \pm 0.5^{\circ} \mathrm{C}$ for 24 to 48 hours. Then, the PA broth and lactose positive bacteria were inoculated into Eosin Methylene Blue agar (EMB agar) and incubated at $35 \pm 0.5^{\circ} \mathrm{C}$ for 24 to 48 hours.

The presence of metallic green colonies endorsed the growth of gram-negative coliform bacteria of $E$. coli. The isolated strains of $E$. coli were then inoculated in lauryl sulfate broth for screening E. coli. Finally, the isolated strains of E. coli were inoculated in EMB agar and then, the grown colonies of $E$. coli were checked throughout an IMViC test. The screened and purified strains of $E$. coli were inoculated in Brain Heart Infusion broth (BHI broth) with the presence of glycerol $15 \%$ and then stored at $-70^{\circ} \mathrm{C}$.

\section{DNA extraction}

The DNA extraction process was achieved via AccuPrep genomic DNA extraction kit (Bioneer, South Korea). In brief, the bacterial suspension was centrifuged at $1200 \mathrm{rpm}$ in $15^{\prime}$ and the pellet was recovered. The pellet was washed by Phosphate Buffered Saline (PBS) and then centrifuged. The supernatant was rinsed out and then, $20 \mu \mathrm{L}$ of proteinase $\mathrm{K}$ was added to the gained pellet. After 
performing the steps, the TE buffer was added to DNA and the final solution was directly used as a PCR template.

Enterobacterial Repetitive Intergenic Consensus-Polymerase Chain Reaction and DNA amplification

For achieving DNA amplification process via ERIC-PCR, a pair of forward and reverse primers was needed. The primers of 5'-ATG TAA GCT CCT GGG GAT TCA C-3' (F) and 5'-AAG TAA GTG ACT GGG GTG AGC G-3' (R) were applied (28, 29). The process was performed in a volume of 25 $\mu \mathrm{L}$, including $1 \mu \mathrm{L}$ of bacterial DNA (E. coli), 12.5 $\mu \mathrm{L}$ of mastermix, $3 \mu \mathrm{L}$ of forward and reverse primers $(1.5 \mu \mathrm{l} / \mathrm{pm}$ per each), and the left volume was filled by $8.5 \mu \mathrm{L}$ of PCR grade water. Finally, the thermocycler was programmed. Simultaneously, negative (PCR grade water) and positive (bacterial DNA of E. coli) controls were used to achieve an accurate observation of the results $(18,28,30,31)$.

\section{Polymerase Chain Reaction Products and Gel Electrophoresis}

The gained products from ERIC-PCR together with loading buffer were run on $1 \%$ gel electrophoresis loaded by SYBR Green; in this practice, a 100-base pair (bp)-DNA marker (manufactured by Fermentas) was used as a standard measuring means. After a 45 minute-gel run, the green bands were observed by UV light and photographed via gel documentation. This stage was repeated twice for checking the accuracy of the results.

\section{Dendrogram and phylogenetic relationships}

The pattern of bands in gel electrophoresis regarding ERIC-PCR products was used as the principle structure for dendrogram calculation. The GelClust is an appropriate and user-friendly software, which can be used for phylogenetic trees and dendrograms via gel electrophoresis photos (32). For constructing computerized dendrogram, the presence and absence of bands were presumed as 1 and 0 , respectively. The dendrogram was designed to unweight pair group method with arithmetic mean (UPGMA), which is categorized in clustering methodologies, and is based on clustering analysis $(29,31,33)$.

\section{Results}

Overall, 115 different strains of $E$. coli were isolated from 120 stool samples (Table 1). The quality and purity of harvested DNA molecules wa recognized via spectrometry. A range of 1.7 to 2.0 resulted from $\mathrm{A}_{260} / \mathrm{A}_{280}$ ratio is acceptable. The $\mathrm{A}_{260}$ / $\mathrm{A}_{280}$ ratio was calculated as 1.8 (34).

The diversity and number of bands gained from gel electrophoresis regarding harvested DNA molecules from isolated E. coli strains in different stool samples in association with hens, sheep, and cows was determined.

Table 1.Identification of Profiles, Bands and Clusters in Association with Escherichia coli Strains

\begin{tabular}{ccccccc}
\hline Methodology & $\begin{array}{c}\text { Unrepeated } \\
\text { profiles }\end{array}$ & $\begin{array}{c}\text { Repeated } \\
\text { profiles }\end{array}$ & $\begin{array}{c}\text { Bands } \\
\text { (Minimum) }\end{array}$ & $\begin{array}{c}\text { Bands } \\
\text { (Maximum) }\end{array}$ & $\begin{array}{c}\text { Diversity of } \\
\text { bands }\end{array}$ & $\begin{array}{c}\text { Number of } \\
\text { clusters }\end{array}$ \\
\hline ERIC-PCR & 115 & 5 & 0 & 6 & 24 & 10 \\
\hline
\end{tabular}

The ERIC-PCR banding patterns have indicated 0 to 46 bands encompassing 380 bp to $3280 \mathrm{bp}$.

The highest frequencies and diversities were seen among $E$. coli strains isolated from hens and sheep stool samples. Moreover, the greatest number of similarities among DNA molecules band patterns were seen in the strains isolated from sheep stool samples. The predominant fragments in DNA fingerprints were determined with sizes of $2900 \mathrm{bp}, 1200 \mathrm{bp}$, and $1200 \mathrm{bp}$ in E. coli strains isolated from stool samples of hens, sheep and cows, respectively; however, the observed bands involved a wide range from 380 to $3280 \mathrm{bp}$.

The GelClust let us design a phylogenetic tree for isolated strains via the presence of a wide range of genetic heterogeneities among their populations. The cluster analysis and related dendrogram are shown in Table 2 and Figure 1, respectively. 
Table 2. Cluster Analysis and Genetic Diversity of the Strains

\begin{tabular}{|c|c|c|c|}
\hline Cluster & $\begin{array}{l}\text { Frequency } \\
\text { of strains }\end{array}$ & $\begin{array}{l}\text { Percentage } \\
\text { of strains }\end{array}$ & Source \\
\hline E1 & 1 & $<1 \%$ & Hens \\
\hline E2 & 1 & $<1 \%$ & Hens \\
\hline E3 & 82 & $69 \%$ & $\begin{array}{l}\text { Hens, } \\
\text { Sheep, } \\
\text { Cows }\end{array}$ \\
\hline E4 & 7 & $5.8 \%$ & $\begin{array}{l}\text { Hens, } \\
\text { Sheep }\end{array}$ \\
\hline E5 & 4 & $3.33 \%$ & Hens \\
\hline E6 & 2 & $1.6 \%$ & $\begin{array}{l}\text { Hens, } \\
\text { Sheep }\end{array}$ \\
\hline E7 & 4 & $3.33 \%$ & Hens \\
\hline E8 & 14 & $11.6 \%$ & $\begin{array}{l}\text { Hens, } \\
\text { Sheep }\end{array}$ \\
\hline E9 & 3 & $2.5 \%$ & Hens \\
\hline E10 & 2 & $1.66 \%$ & Hens \\
\hline
\end{tabular}

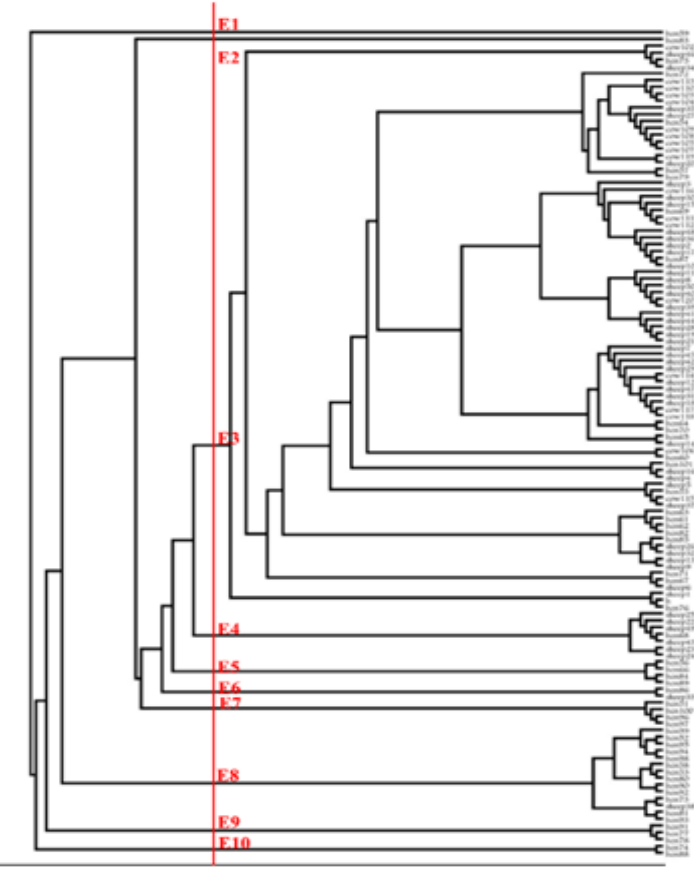

Fig 1. Dendrogram Relating to Isolated Strains of Escherichia coli

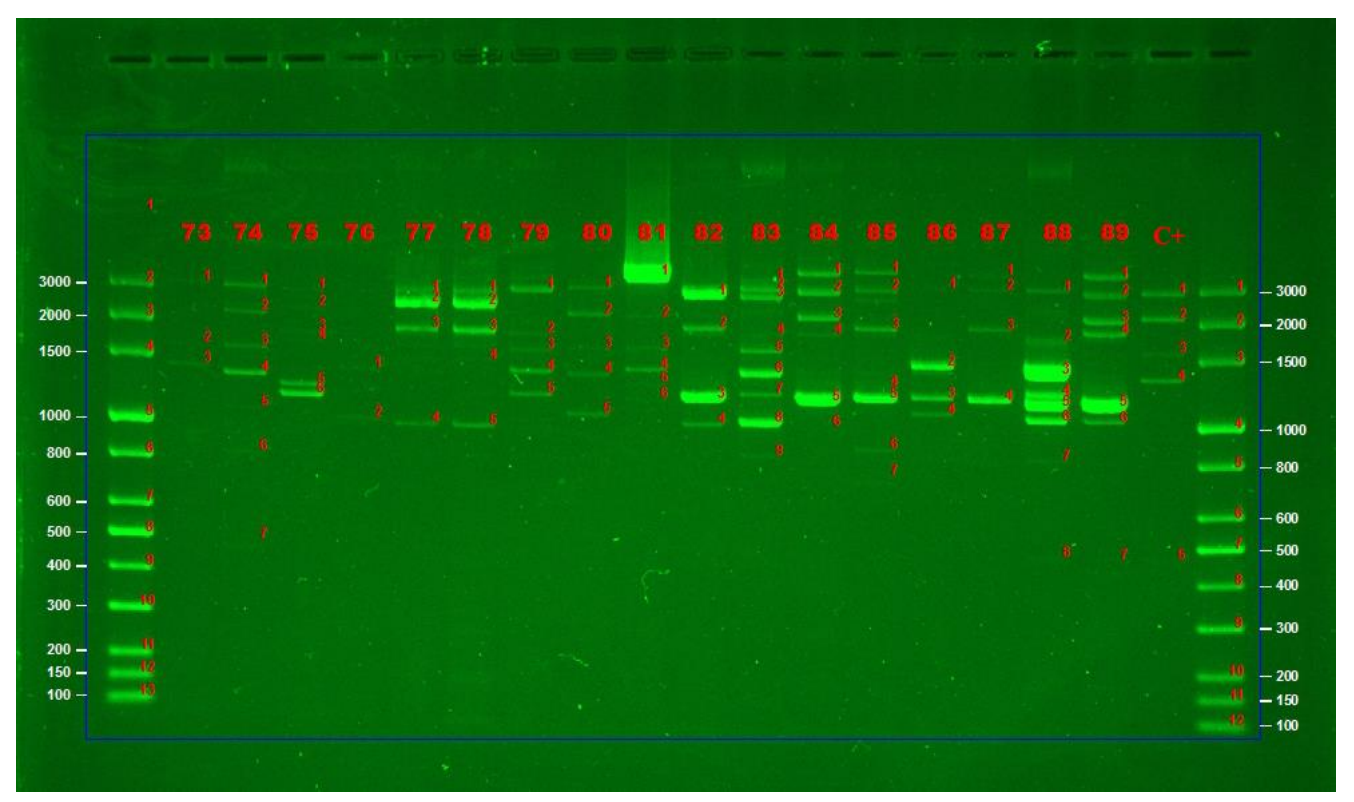

Fig 2. Enterobacterial Repetitive Intergenic Consensus Polymerase Chain Reaction Patterns of Some Escherichia coli Strains

\section{Discussion}

There is a wide range of molecular biology techniques currently available, such as Amplified Fragment Length Polymorphism (AFLP), Amplified Ribosome DNA Restriction Analysis (ARDRA) different types of PCR, microarray, Pulsed Field Gel Electrophoresis (PFGE) Random
Amplified Polymorphism Deoxyribonucleic Acid (RAPD), ribotyping, Restriction Fragment Length Polymorphism (RFLP). Each method and technique has its advantages and disadvantages. Of course, the applied technique in anystudy is in accordance with the study's economic facilities. Some methodologies are sharp with high accuracy 
and discriminatory but they are too expensive. Among the aforementioned techniques, ERIC PCR is rapid, easy to use, and cheap with an acceptable outcome. However, its reproducibility is low (14, $15,35-39)$.

In this study, 120 stool samples were obtained from 3 groups of healthy animals, including hens,

sheep, and cows during 1 year. One hundred and fifteen different strains of $E$. coli were recognized and included for fingerprinting analysis. The ERIC-PCR technique was applied to produce special amplicons for providing specific DNA fingerprint patterns by gel electrophoresis.

The predominant sizes recognized in DNA binding patterns were $2900 \mathrm{bp}$ (hen), $1200 \mathrm{bp}$ (sheep), and $1200 \mathrm{bp}$ (cow). Furthermore, the molecular weight belonging to appeared bands ranged from 380 to $3280 \mathrm{bp}$. The binding patterns resulted in ERIC-PCR and led us to design a dendrogram by the help of the GelClust software, shown in Figure 1.

The binding patterns from gel electrophoresis were used as the basic data for designing a dendrogram using GelClust (32). In the present study, the methodology of UPGMA was applied for designing the dendrogram. Although there are different methods for designing a dendrogram, UPGMA is an easy and appropriate method to calculate, and provides us phenotypic characteristics and a rooted phylogenetic tree $(38$, 40, 41).

There are several investigations, which have used ERIC-PCR for detecting and determining different strains of Enterobacteriaceae family members such as E. coli $(25,42)$.
Casarez et al. collected 650 water samples from natural sources for detecting and genotyping E. coli isolates and used the BioNumerics software for ERIC-PCR fingerprints. They recognized 175 different genotypes from 555 water samples contaminated with human and animal feces (43). Interestingly, they had performed another study in 2007, which was confirmed by their recent investigation (44).

Lipman et al. applied ERIC-PCR for genotyping $E$. coli strains isolated from cows. They have successfully obtained different genotypes of $E$. coli and explained that there was some particular strains, which were the pathogenic agents of mastitis in studied cows (45).

Soltani et al. performed their study on avian hosts for recognizing and genotyping E. coli strains. They recognized 232 to $2690 \mathrm{bp}$ bands on gel electrophoresis step and typed 65 different avian E. coli strains from 95 samples. They confirmed that ERIC-PCR might be a good technique for bacterial genotyping among cheap and simple molecular tools. Otherwise, there are several expensive molecular techniques as mentioned above with high discriminatory power (26).

A wide range of clinical samples like stool, urine and etc. may be used for ERIC-PCR. This method is also helpful for determining multi-drug resistant bacteria (42). The performed investigations confirm the rapidity and simplicity of ERIC-PCR as a cheap advanced molecular technology for different strains of a bacterial species $(17-19,31)$. 


\section{Conclusion}

The DNA profiles were clearly detectable via specific fingerprint patterns. The ERIC-PCR seemed to a good approach for molecular typing of E. coli strains isolated from different animal sources. The ERIC-PCR is recommended for determining different strains pertaining to a bacterial species as a cheap and simple tool. The results of ERIC-PCR can be processed by different types of software, such as GelClust for generating useful dendrograms as invaluable methodology regarding classification of a diversity of bacterial strains, such as E. coli. However, there are also expensive genotyping methods such as AFLP with high accuracy and discriminatory power.

\section{Acknowledgment}

The authors are thankful to Daryoosh Ghasemi for his kind assistance in the sample collection.

\section{Conflict of Interest}

The authors declare that there was no conflict of interests.

\section{References}

1. Clermont O, Olier M, Hoede C, Diancourt L, Brisse S, Keroudean M, et al. Animal and human pathogenic Escherichia coli strains share common genetic backgrounds. Infect Genet Evol 2011;11(3):654-62.

2. Rasko DA, Rosovitz M, Myers GS, Mongodin EF, Fricke WF, Gajer P, et al. The pangenome structure of Escherichia coli: comparative genomic analysis of $E$. coli commensal and pathogenic isolates. J Bacteriol 2008;190(20):6881-93.

3. Wan L, Wang Z-B, Yan Q, Wang X, Lei Y, Zuo L, et al. Genetic diversity of Escherichia coli isolated from commercial swine farms revealed by enterobacterial repetitive intergenic consensus PCR
(ERIC-PCR) and repetitive extragenic palindrome PCR (REP-PCR). Afr J Biotechnol 2013;10(51):10543-50.

4. Touchon M, Hoede C, Tenaillon O, Barbe V, Baeriswyl S, Bidet $\mathrm{P}$, et al. Organised genome dynamics in the Escherichia coli species results in highly diverse adaptive paths. PLoS Genet 2009;5(1):e1000344.

5. Momtaz H, Karimian A, Madani M, Safarpoor Dehkordi F, Ranjbar R, Sarshar M, et al. Uropathogenic Escherichia coli in Iran: serogroup distributions, virulence factors and antimicrobial resistance properties. Ann Clin Microbiol Antimicrob 2013;12(8).

6. Anvarinejad M, Farshad S, Ranjbar R, Giammanco G, Alborzi A, Japoni A. Genotypic analysis of $E$. coli strains isolated from patients with cystitis and pyelonephritis. Iran Red Crescent Med J 2012;14(7):408.

7. Behzadi P, Behzadi E, Ranjbar R. IL-12 Family Cytokines: General Characteristics, Pathogenic Microorganisms, Receptors, and Signalling Pathways. Acta Microbiol Immunol Hung 2016;63(1):1-25

8. Farshad S, Ranjbar R, Japoni A, Hosseini M, Anvarinejad M, Mohammadzadegan R. Microbial susceptibility, virulence factors, and plasmid profiles of uropathogenic Escherichia coli strains isolated from children in Jahrom, Iran. Arch Iran Med 2012;15(5):312-6.

9. Behzadi P, Behzadi E. The microbial agents of urinary tract infections at Central

10. Laboratory of Dr. Shariati Hospital, Tehran, Iran. Turk Klin Tip Bilim. 2008;28(4):445.

11. Jahandeh N, Ranjbar R, Behzadi P, Behzadi E. Uropathogenic Escherichia coli virulence genes: invaluable approaches for designing DNA microarray probes. CEJU 2014;6:11.

12. Behzadi P, Najafi A, Behzadi E, Ranjbar R. Microarray long oligo probe designing for Escherichia coli: an in-silico DNA marker extraction. CEJU 2016;69:105-11.

13. Behzadi P, Behzadi E. Environmental Microbiology. $1^{\text {st }}$ ed. Tehran: Niktab Publisher; 2007.

14. Meacham KJ, Zhang L, Foxman B, Bauer RJ, Marrs CF. Evaluation of genotyping large numbers of Escherichia coli isolates by enterobacterial repetitive intergenic consensus-PCR. J Clin Microbiol 2003;41(11):5224-6. 
15. Behzadi P, Behzadi E, Ranjbar R. Basic Modern Molecular Biology. 1st ed. Tehran: Persian Science \& Research Publisher; 2014.

16. Behzadi P, Ranjbar R, Alavian SM. Nucleic Acid-Based Approaches for Detection of Viral Hepatitis. Jundishapur J Microbiol 2015;8(1).

17. De Gregorio E, Silvestro G, Petrillo M, Carlomagno MS, Di Nocera PP. Enterobacterial repetitive intergenic consensus sequence repeats in yersiniae: genomic organization and functional properties.

J Bacteriol 2005;187(23):7945-54.

18. Ramazanzadeh R, Zamani S, Zamani S. Genetic diversity in clinical isolates of Escherichia coli by enterobacterial repetitive intergenic consensus (ERIC)-PCR technique in Sanandaj hospitals. Iran J Microbiol 2013;5(2):126.

19. Ranjbar R, Naghoni A, Yousefi S, Ahmadi A, Jonaidi N, Panahi Y. The study of genetic relationship among third generation cephalosporin-resistant Salmonella enterica strains by ERIC-PCR. Open Microbiol J 2013;7:142.

20. Ranjbar R, Torabi R, Mirzaie A. Molecular typing of Salmonella enteritidis strains isolated in several laboratory centers in Tehran by ERIC-PCR. SJKUMS 2013;18(2):77-85.

21. Ranjbar R, Karami A, Farshad S, Giammanco GM, Mammina C. Typing methods used in the molecular epidemiology of microbial pathogens: a howto guide. New Microbiol 2014;37(1):1-15.

22. Leung KT, Mackereth R, Tien Y-C, Topp E. A comparison of AFLP and ERIC-PCR analyses for discriminating Escherichia coli from cattle, pig and human sources. FEMS Microbiol Ecol 2004;47(1):1119.

23. Dalla-Costa LM, Irino K, Rodrigues J, Rivera IN, Trabulsi L. Characterisation of diarrhoeagenic Escherichia coli clones by ribotyping and ERIC-PCR. J Med Microbiol 1998;47(3):227-34.

24. Wilson LA, Sharp PM. Enterobacterial repetitive intergenic consensus (ERIC) sequences in Escherichia coli: Evolution and implications for ERICPCR. Mol Biol Evol 2006;23(6):1156-68.

25. Hulton C, Higgins C, Sharp P. ERIC sequences: a novel family of repetitive elements in the genomes of
Escherichia coli, Salmonella typhimurium and other enterobacteria. Mol Microbiol 1991;5(4):825-34.

26. Hosseini MJ, Kaffashian AR. An outbreak of shigellosis due to Shigella flexneri serotype $3 \mathrm{a}$ in a prison in Iran. Arch Iran Med 2010;13(5):413.

27. Soltani M, Peighambari SM, AskariBadouei M, Sadrzadeh A. Molecular typing of avian Escherichia coli isolates by enterobacterial repetitive intergenic consensus sequences-polymerase chain reaction (ERICPCR). Iran J Vet Med 2012;6(3):143-8.

28. Fox JT, Renter DG, Sanderson MW, Thomson DU, Lechtenberg KF, Nagaraja T. Evaluation of culture methods to identify bovine feces with high concentrations of Escherichia coli O157. Appl Environ Microbiol 2007;73(16):5253-60.

29. Versalovic J, Koeuth T, Lupski R. Distribution of repetitive DNA sequences in eubacteria and application to finerpriting of bacterial enomes. Nucleic Acids Res 1991;19(24):6823-31.

30. Versalovic J, Schneider M, De Bruijn FJ, Lupski JR. Genomic fingerprinting of bacteria using repetitive sequence-based polymerase chain reaction. Methods Mol Cell Biol 1994;5(1):25-40.

31. Szczuka E, Kaznowski A. Typing of clinical and environmental Aeromonas sp. strains by random amplified polymorphic DNA PCR, repetitive extragenic palindromic PCR, and enterobacterial repetitive intergenic consensus sequence PCR. J Clin Microbiol 2004;42(1):220-8.

32. MuniRA, Al-Alak SK, Hassan AS, Atia IM. Antibiogram Typing and ERIC-PCR Genotyping of Escherichia coli Isolated from Different Clinical Samples. WJPPS 2014;3(7):27-37.

33. Khakabimamaghani S, Najafi A, Ranjbar R, Raam M. GelClust: a software tool for gel electrophoresis images analysis and dendrogram generation. Comput Methods Programs Biomed 2013;111(2):512-8.

34. Pavlopoulos GA, Soldatos TG, Barbosa-Silva A, Schneider R. A reference guide for tree analysis and visualization. BioData Min 2010;3(1):1.

35. Simona E-S, Diana P, Robertina I, Ionela A, Ileana S, Tatiana V-D. Molecular identification of some yeast strains involved in oral candidosis. Rom Biotechnol Lett 2009;14:4180-6. 
36. Adzitey F, Huda N, Ali GRR. Molecular techniques for detecting and typing of bacteria, advantages and application to foodborne pathogens isolated from ducks. 3 Biotech 2013;3(2):97-107.

37. Wassenaar TM, Newell DG. Genotyping of Campylobacter spp. Appl Environ Microbiol 2000;66(1):1-9.

38. Elboutahiri N, Thami-Alami I, Zaïd E, Udupa SM. Genotypic characterization of indigenous Sinorhizobium meliloti and Rhizobium sullae by repPCR, RAPD and ARDRA analyses. Afr J Biotechnol 2009;8(6): 979-985.

39. Wei G, Pan L, Du H, Chen J, Zhao L. ERICPCR fingerprinting-based community DNA hybridization to pinpoint genome-specific fragments as molecular markers to identify and track populations common to healthy human guts. J Microbiol Methods 2004;59(1):91-108.

40. Laciar A, Vaca L, Lopresti R, Vega A, Mattana C, De Centorbi O. DNA fingerprinting by ERIC-PCR for comparing Listeria spp. strains isolated from different sources in San Luis, Argentina. Rev Argent Microbiol 2006;38(2):55.

41. Sankarasubramanian J, Vishnu US, Sridhar J, Gunasekaran P, Rajendhran J. Pan-Genome of Brucella Species. Indian J Microbiol 2015;55(1):88-101.
42. Davis J, Akella S, Waddell P, editors. Accelerating phylogenetics computing on the desktop: experiments with executing UPGMA in programmable logic. Engineering in Medicine and Biology Society, 2004 IEMBS'04 26th Ann Int Conf IEEE 2004.

43. Ranjbar R, Ghazi FM. Antibiotic sensitivity patterns and molecular typing of Shigella sonnei strains using ERIC-PCR. Iran J Public Health 2013;42(10):1151.

44. Casarez EA, Pillai SD, Di Giovanni GD. Genotype diversity of Escherichia coli isolates in natural waters determined by PFGE and ERIC-PCR. Water Res 2007;41(16):3643-8.

45. Casarez EA, Pillai SD, Mott JB, Vargas M, Dean KE, Di Giovanni GD. Direct comparison of four bacterial source tracking methods and use of composite data sets. J Appl Microbiol 2007;103(2):350-64.

46. Lipman LJ, de Nijs A, Lam TJ, Gaastra W. Identification of Escherichia coli strains from cows with clinical mastitis by serotyping and DNA polymorphism patterns with REP and ERIC primers. Vet Microbiol 1995;43(1):13-9.

\section{How to Cite This Article:}

Ranjbar R, Tabatabaee A, Behzadi P, Kheiri R. Enterobacterial Repetitive Intergenic Consensus Polymerase Chain Reaction (ERIC-PCR) Genotyping of Escherichia coli Strains Isolated from Different Animal Stool Specimens. Iranian Journal of Pathology. 2016:25-34. 